\title{
PROCESSO DE TOMADA DE DECISÃO E A RACIONALIDADE ADMINISTRATIVA NA MUDANÇA DO SISTEMA DE PRODUÇÃO CONVENCIONAL PARA O DE BASE ECOLÓGICA NA AGRICULTURA FAMILIAR
}

\author{
Lirio José Reichert \\ Mário Conill Gomes ${ }^{2}$
}

\section{RESUMO}

O processo administrativo passa pela tomada de decisões e para isto são necessários critérios e racionalidade para tomá-las corretamente. O processo decisório é influenciado pelos meios socioeconômico e ambiental, cujos elementos nem sempre podem ser quantificados por métodos simplificados. Neste trabalho, foram contextualizados os aspectos decisionais de 20 agricultores familiares entrevistados, que decidiram mudar do sistema de produção convencional para o de base ecológica. Os dados apurados apontam para questões relacionadas à falta de mercado, baixa rentabilidade, problemas de saúde, preocupações com o meio ambiente e a quase totalidade buscou a diversificação da produção, a inserção no mercado e cuidados com a saúde e meio ambiente como alternativas sustentáveis nas dimensões econômica, social e ambiental. Neste sentido, a agroecologia surgiu como alternativa para um grupo de agricultores familiares que, há mais de quinze anos, se organizou e se estruturou para a mudança da matriz produtiva com enfoque agroecológico e ação participativa.

Palavras-chave: racionalidade administrativa; agricultura familiar; agroecologia

1 Doutorado programa pós-graduação sistema de produção agrícola familiar da Universidade Federal de Pelotas (SPAF/OFpel); e-mail: lírio@cpact.embrapa.br

2 Instituição: Universidade Federal de Pelotas - UFPel. Dr. em Engenharia de Produção de UFSC (Engenheiro agronomo); e-mail: mconill@ufpel.edu.br

Agr. Fam. Belém n 9 p. 121-144 2009 


\section{ABSTRACT}

The administrative process must make decisions, either in relation to our private lives or to a great enterprise. It does not matter the extent and the importance of the decisions, what matters is that we need rationality and a standard to make right decisions. The decision process is strongly influenced by the social-economic environment and by the environment itself, whose elements cannot always be quantified or isolated by simplified and reductionist methods. In this work were contextualized the family farmer's decisions, the strategies of the organization, and a family farmer group decision who decided to change from the conventional system of production to the ecological system of production. Collected data have pointed out some questions related to a lack of market, low rentability, health problems, apprehension about environment, and almost everyone, have looked for the diversification of the productive unit to insert into market, health and environment care as sustainable alternatives in the economic issue, and social and environment scope.

Keywords: administrative rationality; family agriculture; agroecology

\section{INTRODUÇÃ}

A qualificação dos processos de produção da agricultura familiar no Brasil tem se destacado como uma alternativa para a fixação do homem no campo. Neste sentido, tem sido alvo de discussões não somente pelos governos, mas também nos meios acadêmicos, órgãos de pesquisa, extensão e vários segmentos cooperativos voltados para o interesse da classe trabalhadora rural. O Governo Federal tem implementado políticas públicas direcionadas a esse setor, visando à busca de estratégias de apoio ao agricultor com vistas à sustentabilidade do sistema produtivo.

A agricultura familiar, enquanto geradora do desenvolvimento agropecuário, é ainda um processo em construção. Ela busca uma identidade própria para consolidar-se como um segmento importante na produção de alimentos, na geração de emprego e distribuição de renda, na preservação 
de produção convencional para o de base ecológica na agricultura familiar

da biodiversidade, na manutenção e preservação dos recursos naturais, enfim, nos múltiplos propósitos de organização social, cultural e econômica no contexto que estiver inserida. No entanto, para o seu fortalecimento e valorização depende de um conjunto de fatores econômicos, sociais, políticos e culturais que vem sendo articulados por uma diversidade de organizações, pessoas e instrumentos. Sem dúvida, o Estado tem um papel importante nesse processo e seu principal objetivo é viabilizar e implementar políticas públicas de crédito, assistência técnica, pesquisa, apoio organizacional que cheguem até as bases produtivas, por mais distantes que elas se encontrem. Quanto mais estas políticas conseguirem se transformar em respostas à estratégia geral de desenvolvimento com sustentabilidade e, ao mesmo tempo, às demandas concretas e imediatas da realidade conjuntural, mais adequadamente cumprirão o seu papel.

$\mathrm{Na}$ agricultura familiar, o processo de decisão e ação implica confrontar, permanentemente, os objetivos e metas do agricultor e sua familia com um conjunto de condicionantes externos associados ao meio ambiente, ou de natureza econômica, social, cultural e ideológico. Muitas decisões são tomadas levando-se em conta a percepção que os agentes (familia) têm de sua situação e das finalidades atribuídas às suas unidades de produção (LIMA et al., 2005).

Simon (1970), ao justificar o processo de tomada de decisão adotada pelo homem, apresenta uma racionalidade mais próxima do perfil de um comportamento humano, que busca a atender a "soluções satisfatórias" e não ótimas. Descreve ainda Simon de que o ser humano possui uma capacidade limitada de processar todas as informações disponíveis e tomar as melhores decisões. Toma sim, as decisões satisfatórias dentre as alternativas que lhe são oferecidas.

Com isso, a racionalidade administrativa pode ser descrita como as decisões dos agentes quanto à mobilização dos seus recursos (meios) para atingir objetivos (fins) determinados, sendo as ações administrativas (as escolhas, as decisões) condicionadas pelos objetivos e finalidades impostos pelo agente (família) à unidade de produção (LIMA et al., 2001). Por outro lado, Darolt (2000) percebe a racionalidade do agricultor como a capacidade de planificar, organizar, agrupar, dirigir, coordenar e controlar o uso de recursos, avaliar os fatores e fixar os objetivos da unidade de produção, de maneira similar a Lima et al.(2005). 
Todas essas abordagens mostram que os agricultores familiares constituem um segmento muito importante que deve ser tratado com distinção e respeito, de modo que são várias as abordagens e questionamentos considerados pelos agricultores na hora da tomada de decisões importantes. Assim, o agricultor procura estabelecer uma sintonia entre a racionalidade decisional mais adequada ao contexto da unidade de produção e as decisões propriamente ditas a serem tomadas.

Na agricultura, especialmentena de base familiar, não tem sido diferente. A busca pela sustentabilidade econômica, social e ambiental está diretamente relacionada aos processos de transformação dos meios de produção, da mudança nos sistemas produtivos, do manejo do agroecossistema, das políticas públicas, da participação dos técnicos, do envolvimento dos agricultores, das entidades organizacionais e representativas dos agricultores comprometidas com o crescimento e o desenvolvimento sustentável da agricultura familiar.

Para o desenvolvimento da Agroecologia, muitos desafios e paradigmas precisaram (e ainda precisam) ser quebrados. Em muitas organizações e entidades de ensino e pesquisa, a mudança de foco nas pesquisas e estratégias de produção, representa um grande desafio pessoal e institucional. A agroecologia tem como premissa metodológica básica a pesquisa participativa com enfoque sistêmico, multidisciplinar e multi-institucional e que valoriza o saber popular e os conhecimentos empíricos dos agricultores. Isto representa um desafio para muitas organizações e pesquisadores que estão acostumados a um enfoque científico analítico e compartimentalizador.

A Agroecologia surge como alternativa para as famílias de agricultores e traz consigo a perspectiva de mudança na matriz produtiva, visando manter a unidade de produção de uma forma sustentável nas dimensões econômica, social e ambiental. Para Caporal e Costabeber (2002), a Agroecologia corresponde, ao campo de conhecimentos que proporciona as bases científicas para apoiar o processo de transição do modelo de agricultura convencional para estilos de agriculturas de base ecológica ou sustentáveis, assim como do modelo convencional de desenvolvimento a processos de desenvolvimento rural sustentável. A partir de enfoques sustentáveis, da ação participativa e da interação com os recursos naturais, os autores passaram a defender a 
terminologia de "agricultura de base ecológica" como sendo aquela que interage com o meio ambiente, ou seja, há uma aproximação do homem com a natureza e do agroecossistema ${ }^{3}$.

Este trabalho tem por objetivos contextualizar e analisar os aspectos decisionais de agricultores familiares da Associação Regional de Produtores Agroecologistas da Região Sul do RGS - ARPA-SUL ${ }^{4}$ e da Cooperativa Sul Ecológica $^{5}$ identificando os motivos que levaram esses agricultores a mudar a matriz produtiva, saindo do modelo de produção convencional, identificado como de agricultura intensiva, onde o uso de capital e insumos externos, assim como o solo, são predominantes, para o estilo de produção de base ecológica, em que as atividades são ecologicamente equilibradas, socialmente justas e economicamente viáveis rompendo desse modo, paradigmas tecnológicos e institucionais estabelecidos. Ademais, esses resultados poderão servir de base orientadora e como fonte de estímulo, para outros agricultores familiares na tomada de decisão.

\section{REVISÃO BIBLIOGRÁFICA}

O uso racional dos recursos naturais e econômicos na unidade familiar deve permitir que os objetivos e metas de produção proposto sejam alcançados no menor tempo possível e com o mínimo, ou seja, da forma mais econômica possível e sustentável.

3 Agroecossistema segundo Conway, (1993 apud CASALINHO, 2003) é uma parcela de terra utilizada com um determinado sistema de produção constituído por um conjunto ordenado de atividades, manejadas de tal forma que propiciem respostas ao entorno fisico, biológico e socioeconômico, de acordo com os objetivos, preferências e recursos dos agricultores.

4 Associação Regional de Produtores Agroecologistas da Região Sul do RGS, fundada em 1995 por um grupo de agricultores que optaram produzir no sistema de base ecológica. Foi criada com o objetivo de viabilizar a pequena propriedade e também como meio para superar, em conjunto, os problemas comuns pertinentes aos agricultores entre eles, organização o processo de produção e comercialização. Por meio da Associação, tiveram acesso direto ao mercado por meio das feiras agroecológicas. Conta com 35 famílias divididas em 7 grupos, distribuídas em 5 municípios da região Sul do RS.

5 Cooperativa Sul Ecológica de Agricultores Familiares criada em 2001, com o objetivo de ampliar o universo de agricultores de base ecológica. Neste sentido, a cooperativa fomentou a produção, a organização social, criou canais de comercialização e abastecimento, promovendo uma valorização da produção de base ecológica, bem como a formação e a capacitação dos cooperados e jovens agricultores. Conta com 180 familias associadas e organizadas neste processo, distribuídas em 8 municípios da Zona Sul.

Agr. Fam. Belém n 9 p. 121-144 2009 
Lima et al. (2005, p.35), ao descreverem o uso racional dos recursos de uma unidade de produção familiar, dizem que "a utilização racional de recursos corresponde ao seu emprego e a sua adequação, da forma mais econômica possível tendo em vista a consecução de fins determinados". Não se pode fazer uma boa administração dos recursos disponíveis na unidade familiar sem que haja racionalidade no uso dos mesmos com vistas ao alcance dos objetivos estabelecidos. Neste sentido, os mesmos autores complementam dizendo que "a racionalidade administrativa deve ser considerada própria e contingente de cada indivíduo da organização". No sentido geral, o processo administrativo se configura como sendo um continuum integrado entre decisão e ação. Os mesmos autores afirmam que o processo de decisão e ação implica numa confrontação permanente entre os objetivos do agricultor e sua família e um conjunto de condicionantes bioclimáticos ligados ao processo de produção e ao meio socioeconômico. Eles concluem dizendo que:

As decisões e ações dos agricultores familiares relativas à condução de suas atividades de produção são coerentes e racionais. Elas visam a atender um ou mais objetivos no quadro de ações percebidas como possíveis pelo grupo familiar, tendo em vista a percepção que o(s) agente(s) tem de sua situação e das finalidades atribuídas às suas unidades de produção (LIMA et al. 2005 p.66).

Ainda de acordo com estes autores, a unidade de produção deve ser vista como um sistema. Este tipo de enfoque permite analisar e entender a propriedade como um todo, de forma dinâmica, onde estão presentes e se relacionam entre si os componentes físicos, químicos e biológicos. Estes autores descrevem que "a unidade de produção é um sistema aberto que mantém relações com o meio ambiente físico, socioeconômico e cultural e que retém desse conjunto, incluindo a unidade de produção, os elementos que determinam o funcionamento do sistema".

Na Figura 1, pode-se observar como ocorrem essas relações dentro da unidade familiar. No subsistema decisional é onde se articula, a partir de um subsistema que determina as finalidades da unidade de produção, seus projetos que visam mantê-la de um lado de forma dinâmica e coesa para alcançar os projetos definidos e, de outro, a gerência que é onde se estabelecem seus objetivos estratégicos e que, geralmente, são de longo prazo. Neste subsistema há que se fazer avaliações constantes e muitas vezes deve-se 
Processo de tomada de decisão e a racionalidade administrativa na mudança do sistema de produção convencional para o de base ecológica na agricultura familiar

proceder adaptações em função de fatos que possam interferir nos resultados planejados.

O subsistema de operações ou de produção tem por finalidade implementar um conjunto de ações para viabilizar o processo produtivo, são decisões que dizem respeito a técnicas de cultivo, operações, manejo de sistemas de produção, estratégias cotidianas de curto prazo e que viabilizem a unidade de produção. O subsistema de informações tem a função de dialogar entre o subsistema decisional e de operações no sentido de se poder controlar o processo produtivo para que no nível gerencial se possam tomar as decisões da melhor forma possível.

Assim, pode-se afirmar que o processo de tomada de decisão em uma unidade de produção familiar nem sempre é fácil. Há um conjunto de fatores internos e externos que podem auxiliar ou dificultar tais decisões. Na maioria dos casos quem executa os subsistemas em todas as fases é a mesma pessoa, ou seja, o agricultor.

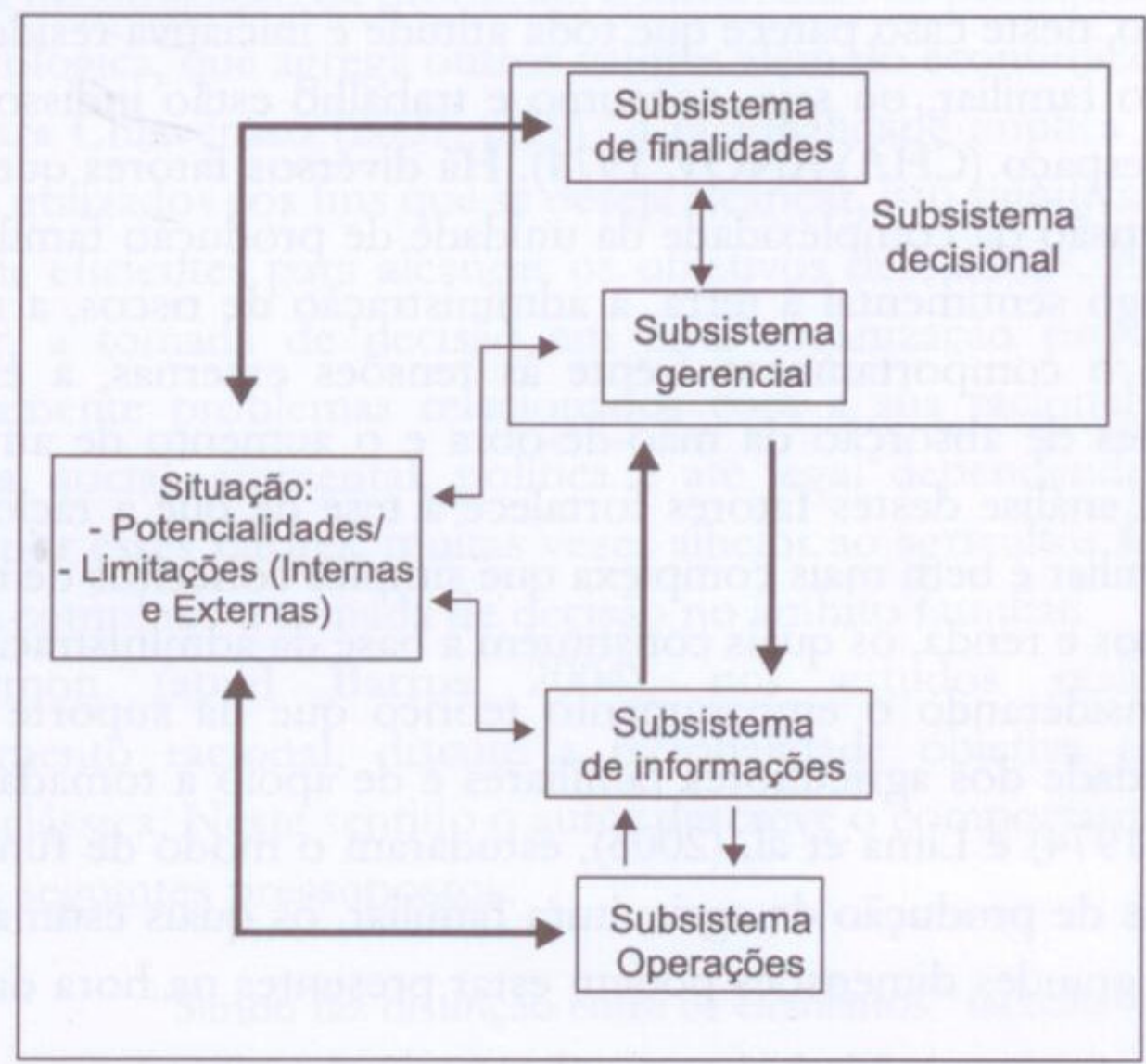

Fonte: BONNEVIALE et al. (1989 apud LIMA et.al. 2005, p.62)

Figura 1. Representação dos subsistemas de operação, decisional e informação do sistema família - unidade de produção. 
No estudo sobre os meios e as técnicas de apoio à decisão tem se observado um nível de investimento cada vez maior por parte das organizações, indústrias e empresas. A obra de Ensslin et al. (2001) concretiza a construção de um quadro metodológico guiado por concepções construtivistas de apoio à decisão, onde se assume a posição de que o poder de decidir não pertence ao mediador. Porém, ainda se observa pouco investimento de tal ferramenta acadêmica em sistemas produtivos de racionalidade mais complexa, encontrando melhor aplicação em empresas agrícolas, cooperativas, empresas privadas, entre outras.

Analisar a unidade de produção familiar é reconhecer e compreender suas particularidades (LIMA et al., 2005 e ENSSLIN et al., 2001). Ambos discutem o processo decisório tomando como base as construções epistemológicas de Roy (1993), que sustenta uma vertente construtivista como pressuposto de valorização dos decisores e agidos enquanto verdadeiros protagonistas da tomada de decisão. Neste sentido, reafirma-se que a unidade de produção familiar não responde a mesma lógica das empresas capitalistas. Ao contrário, neste caso parece que toda atitude e iniciativa residem na busca da satisfação familiar, ou seja, consumo e trabalho estão indissociavelmente no mesmo espaço (CHAYANOV, 1974). Há diversos fatores que auxiliariam na compreensão da complexidade da unidade de produção familiar, entre os quais o apego sentimental à terra, a administração de riscos, a relação com o mercado, o comportamento frente às tensões externas, a existência de possibilidades de absorção da mão-de-obra e o aumento de atividades não agrícolas. A análise destes fatores fortalece a tese de que a racionalidade da unidade familiar é bem mais complexa que simples conceitos de organização, receita, custos e renda, os quais constituem a base da administração clássica.

Considerando o embasamento teórico que dá suporte em termos da racionalidade dos agricultores familiares e de apoio à tomada de decisão, Chayanov (1974) e Lima et al. (2005), estudaram o modo de funcionamento dos sistemas de produção da agricultura familiar, os quais estimam que pelo menos três grandes dimensões podem estar presentes na hora da tomada de decisões:

a)

Econômica: obtenção de um produto destinado a compensar os desembolsos monetários da produção. É a obtenção de um excedente, que para o agricultor familiar é a diferença entre a renda bruta monetária anual e os desembolsos monetários; 
Processo de tomada de decisão e a racionalidade administrativa na mudança do sistema de produção convencional para o de base ecológica na agricultura familiar

b) Social: relacionada à valorização da mão-de-obra familiar e à redução do esforço do trabalho. Valorizam as relações com a comunidade, com os vizinhos, há um apoio recíproco de troca de serviços, máquinas e até financeiro;

c) Risco: estabilidade da familia frente a fatores não controlados, tais como o clima e o mercado. A maior aversão ao risco leva os agricultores a diversificarem a produção e os investimentos, isto é, ampliar o leque de cultivos e/ou criações inclusive para o autoconsumo.

A produção de base ecológica se insere neste contexto, pois o agricultor ao decidir mudar seu sistema de produção, está também assumindo determinados riscos inerentes ao processo de produção, sejam eles de ordem tecnológica, estruturais, ideológicos, ambientais ou econômicos. Decide confrontar-se com o poder econômico, tendo que quebrar paradigmas de ordem econômica, ambiental e social. $\mathrm{O}$ modelo tradicional de produção de certa forma se apresenta organizado, estruturado tendo como metas e objetivos a maximização da produção, contrariando os princípios da produção de base ecológica, que agrega outros valores além do econômico.

Para Chiavenato (2007, p.59) "a racionalidade implica na adequação dos meios utilizados aos fins que se deseja alcançar, isto significa fazer uso dos meios mais eficientes para alcançar os objetivos desejados". Ainda segundo este autor, a tomada de decisão em uma organização procura satisfazer simultaneamente problemas relacionados com a sua racionalidade técnica, econômica, social, ambiental, política e até legal dependendo da situação. Portanto, por esses fatores, muitas vezes alheios ao agricultor familiar, tornase difícil e complexo a tomada de decisão no âmbito familiar.

Simon (apud Barros 2004), nos estudos realizados sobre comportamento racional, discute a racionalidade objetiva encontrada na teoria neoclássica. Neste sentido o autor descreve o comportamento humano, usando os seguintes pressupostos:

"Simon faz distinção entre os elementos "factuais" e os "de valor" em uma decisão, sendo que toda decisão envolve ambos os tipos de elementos. A distinção é, tal como feita por ele, puramente teórica, na medida em que ambos os aspectos - factual e de valor - na prática se misturam, necessariamente, em qualquer decisão. Cada

Agr. Fam. Belém n 9 p. 121-144 2009 
decisão envolve a seleção de um objetivo e de um comportamento relevante ao seu cumprimento, cada objetivo por sua vez pode ser instrumental para um objetivo mais amplo. Como tipos ideais, na medida em que esta seleção trate de objetivos "finais" teremos "julgamentos de valor", e na medida em que trate da forma de levar estes objetivos a cabo teremos "julgamentos de fato". (Simon apud BARROS, 2004, p. 60).”

Portanto uma escolha é uma seleção dentre inúmeras alternativas comportamentais possíveis. Uma decisão é o processo por meio do qual esta seleção é efetuada e, uma vez definida, aparentemente não há empecilhos para a sua realização.

Uma decisão envolve sempre um comportamento racional, ou seja, que esteja totalmente adaptado ao ambiente da decisão. Uma decisão somente pode ser racional se for propositada, motivada, se tiver objetivos definidos, sendo necessário para isto comparar os meios alternativos com os fins visados. Para Barros (2004), a racionalidade objetiva (racionalidade laplaciana) exige um conhecimento completo das alternativas e das consequências que se seguem a cada alternativa e isto exige uma antecipação perfeita do que poderá ocorrer; exige que todas as alternativas de comportamento possíveis sejam consideradas. O autor cita que no centro da teoria comportamental de Simon estão a tomada de decisão e a solução de problemas. O caminho que leva à ação racional é o que torna claro os propósitos ou motivações, as escolhas/ decisões e a ação.

Lopes et al. (2005), em trabalho com agricultores ecológicos da feira da ARPA-SUL, onde a unidade estudada é composta pelo casal, teve por objetivo buscar a motivação dos filhos para retornarem à propriedade, pois consideram a reprodução da família às voltas da unidade de produção como sendo o maior objetivo e a meta traçada por eles. Para estes autores, a lógica de produção destas famílias é investir no negócio agrícola para proporcionar o incremento da renda familiar, sem necessariamente aumentar a produtividade das parcelas cultivadas. Mantém-se a prática de troca de serviços e produtos.

Outro desafio apontado por Lopes et al., (2005) e que exige tomada de decisão pela família, é na busca de novas alternativas apoiadas pela ARPASUL e que necessitam de investimentos para realizar a transformação caseira 
Tousceso de tomada de decisao e a racionalidade administrativa na mudança do sistema de produção convencional para o de base ecológica na agricultura familiar

de produtos "in natura". Estes autores identificam que o grande desafio apontado pela família é: "Investir ou não na indústria caseira e ampliar as opfões de negócios na feira ecológica?” Essa dúvida que paira sobre esta família ¿́ a mesma de tantas outras, porque o incremento de uma nova alternativa de produção, seja no cultivo, na criação ou no processo de industrialização como é este caso, implica em novos investimentos ou incremento de mão-de-obra.

Para Darolt (2000) a racionalidade do agricultor é a capacidade de planificar, organizar, agrupar, dirigir, coordenar e controlar o uso de recursos, avaliar os fatores e fixar os objetivos da unidade de produção. $\mathrm{O}$ agricultor fixa seus objetivos segundo um conjunto de fatores, necessidades e desejos. A racionalidade segue os princípios da administração e do gerenciamento da unidade de produção que estão divididos em quatro etapas: planejamento, organização, diresão e controle. É na fase do planejamento que o agricultor toma suas decisões, determina os objetivos e como e o que deve ser feito para alcançá-los.

\section{MÉTODO DE OBTENÇÃO DOS DADOS}

Para o levantamento das informações, foi selecionado, aleatoriamente, um grupo de 20 agricultores agroecologistas que em determinado momento de suas vidas tomaram a decisão de mudar do sistema de produção convencional ${ }^{6}$ para o de base ecológica ${ }^{7}$ e que realizam a comercialização de seus produtos em feiras ecológicas e pontos fixos organizados por suas respectivas entidades (ARPA-SUL, Cooperativa Sul Ecológica) e como entidade assistencial o Centro de Apoio ao Pequeno Agricultor - $\mathrm{CAPA}^{8}$. A região de abrangência dessas

6 O modelo de produção convencional refere-se ao sistema de produção por meio do uso intensivo de insumos e fertilizantes químicos, com um grande aporte tecnológico, cujo objetivo é obter o máximo de rendimento por área cultivada. Este modelo intensificou-se após a Segunda Guerra Mundial motivado pela escassez de alimentos, culminando na década de 70, com a chamada "Revolução Verde"

7 Sistema de produção de base ecológica consiste na produção agropecuária de alimentos isentos do uso de agrotóxicos, promovendo a saúde humana e a proteção ambiental. Promove a interação entre o homem e a natureza, preservando a biodiversidade, os ciclos biológicos das espécies vegetais e animais e atividade biológica do solo. Baseia-se no uso mínimo de produtos externos à propriedade e no manejo de práticas que restauram, mantém e promovem a harmonia e o equilíbrio ecológico do sistema.

8 CAPA - Organização Não-Governamental ligada a Igreja Evangélica de Confissão Luterana no Brasil - IECLB com foco de atuação por justiça social. Atua desde 1978 nos três estados da região Sul do Brasil (PR, SC e RS), e visa contribuir para o fortalecimento da agricultura 
organizações compreende 25 municípios que estão inseridos no Território Zona Sul do RS ilustrados na Figura 2.

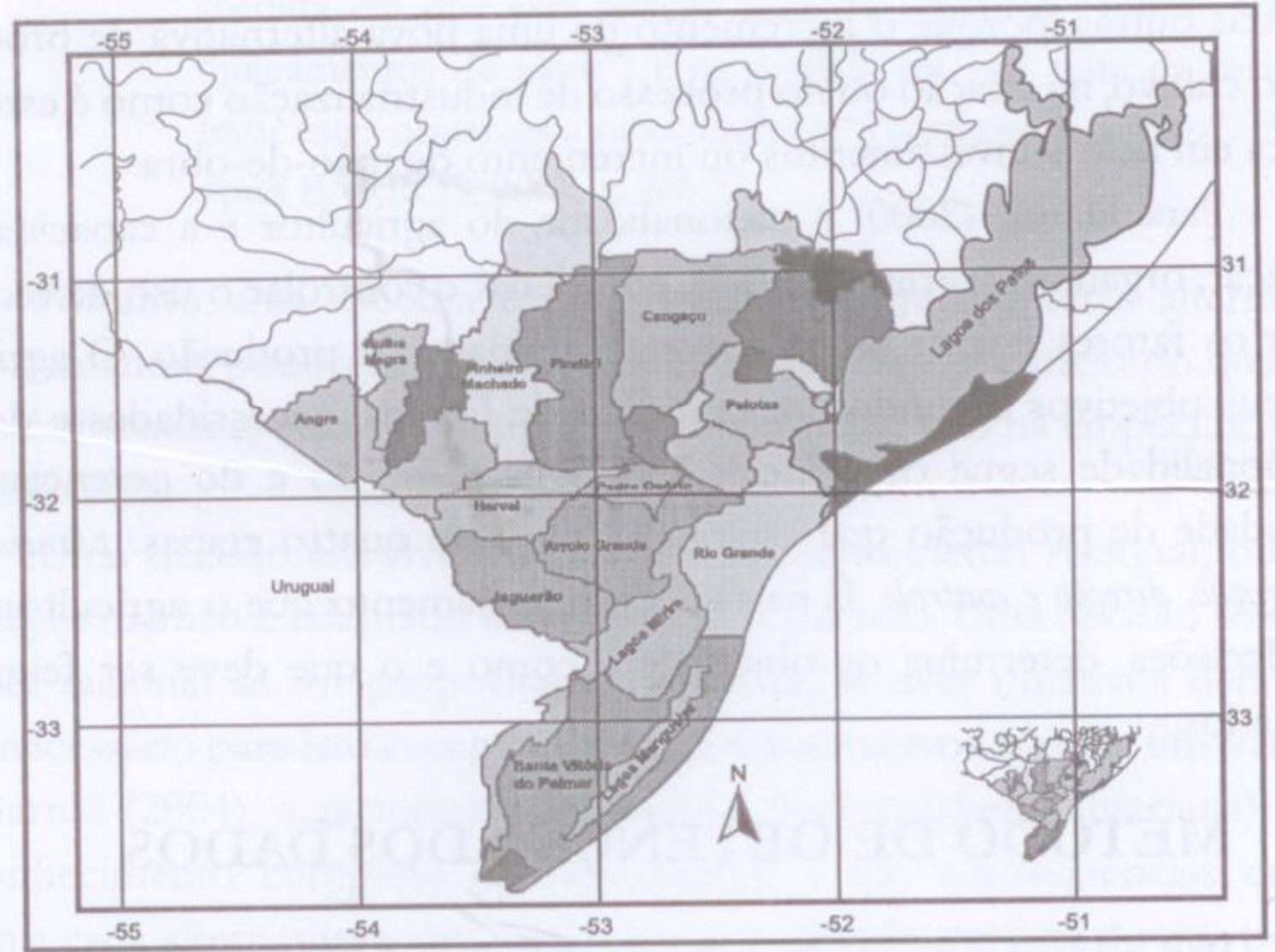

Figura 2. Localização espacial no estado do Rio Grande do Sul, do Território Zona Sul com os municípios integrantes.

Nas entrevistas, procurou-se obter informações da trajetória desses agricultores, buscando respostas para o seguinte questionamento: qual foi o momento ou de que forma ocorreu o processo de mudança que o levou a tomar a decisão de mudar do sistema de cultivo convencional para o de base ecológica?

Neste sentido, foi elaborado um questionário estruturado, composto com as seguintes perguntas:

familiar, na construção de sujeitos sociais a partir da cooperação agrícola, agroindustrialização e da comercialização, tendo a agroecologia como base tecnológica e o protagonismo como princípio ético, justiça social, respeito à diversidade - biológica, cultural, ética e religiosa, potencializando a construção de um projeto de desenvolvimento rural sustentável. Assim, o CAPA, trabalha pela organização dos agricultores em associações, cooperativas e redes, permitindo e facilitando a inserção dos mesmos nos diversos mercados, com maior autonomia, tornando-os sujeitos ativos. 
Processo de tomada de decisão e a racionalidade administrativa na mudança do sistema de produção convencional para o de base ecológica na agricultura familiar

1- Há quanto tempo é produtor ecológico?

2- $\quad$ que cultivava antes na propriedade e de que forma?

3- Como era realizada a venda da produção?

4- O que o levou a tomar a decisão de mudar o sistema de produção?

5- Quais os sistemas de cultivos existentes agora na unidade?

6- $\quad$ O que mudou após ter tomado esta decisão?

7- Qual a avaliação da família sobre esta mudança?

As entrevistas foram realizadas nas residências dos agricultores e nos pontos de venda (feiras livres e pontos fixos) no mês de maio de 2008 e, para facilitar a coleta e registro das informações, foi utilizado um gravador com a concordância dos agricultores. Nas Figuras 3 e 4, pode-se visualizar dois destes pontos de venda, sendo um deles em feira livre, realizada todos os sábados pela manhã e, outro um ponto fixo, aberto ao público de segunda a sexta-feira. Figura 3. Ponto de venda da Feira da ARPA-SUL, no dia de comemoração dos 12
anos de inauguração, em 2007 


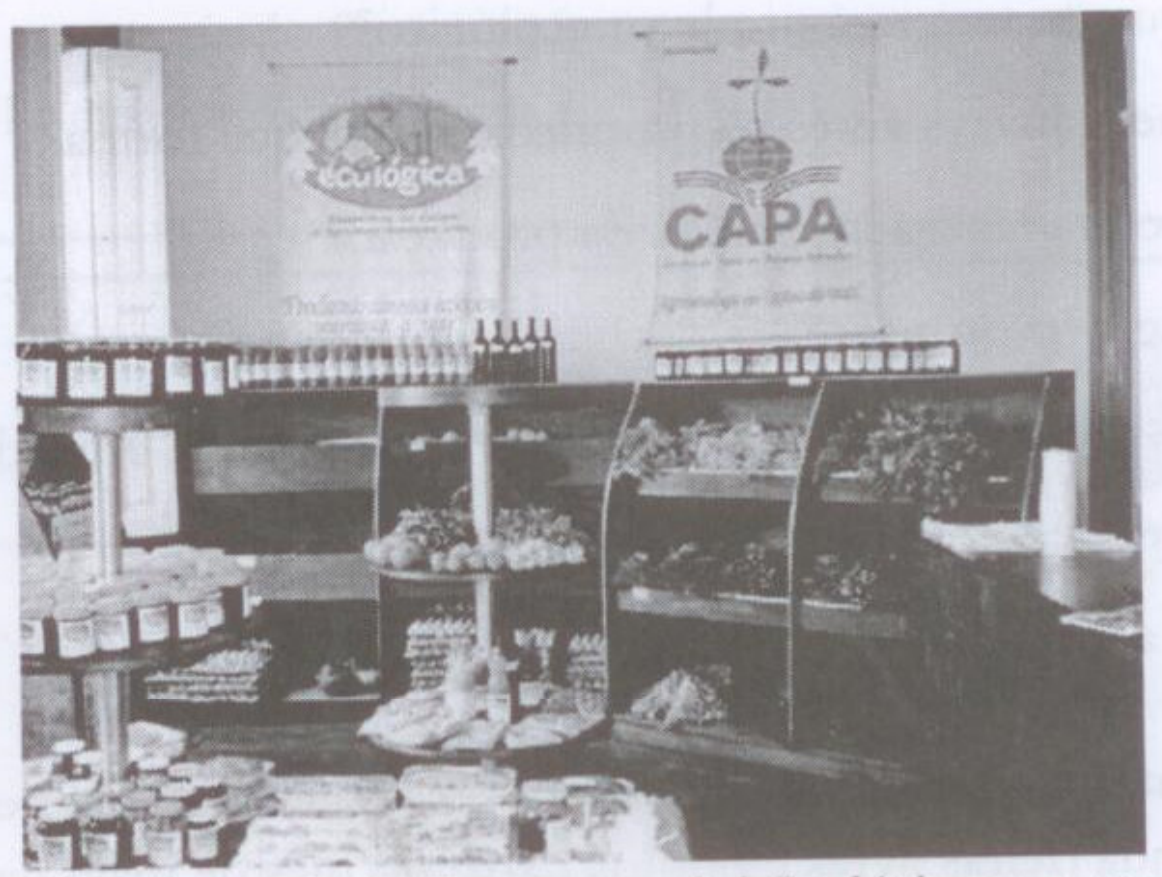

Figura 4. Ponto fixo de venda da Cooperativa Sul Ecológica no centro da cidade de Pelotas/RS

\section{RESULTADOS E DISCUSSÃO}

Analisando o conteúdo das entrevistas, constatou-se que houve muita similaridade nos motivos que levaram este grupo de agricultores a mudar de sistema de produção. A síntese dessas entrevistas está descrita no Quadro 1. Ao analisar o conteúdo das respostas dos 20 agricultores concluiu-se que, independentemente do tempo que estão inseridos no proceśso de produção de base ecológica, os dados apontaram para três questões mais relevantes como: o vínculo com a baixa renda agrícola; a falta de opções de mercado e relacionado com a saúde (do agricultor, da família e do consumidor). Outros motivos também foram apontados, porém esses se destacaram e merecem atenção especial. De acordo com as informações contidas no quadro, houve 14 respostas relacionadas com a baixa rentabilidade; 12 com poucas opções de mercado; 10 com problemas de saúde familiar; 4 preocupados com o meio ambiente, principalmente com o esgotamento do solo em função do modelo de produção convencional, baseado no uso intensivo do solo, fertilizantes químicos e muitos defensivos agrícolas.

Por outro lado, ao analisar as alternativas para sair desta situação empobrecedora e mudar a matriz produtiva, visualizando uma situação melhor, as repostas foram da seguinte maneira: 13 agricultores disseram que 
buscavam uma diversificação da atividade para poder adequar-se ao mercado e conseqüentemente obter mais renda; 9 foram relacionadas à busca de melhor qualidade de vida familiar; 7 associaram preocupações com o meio ambiente envolvendo solo, água, fauna e quatro deles tiveram a preocupação direta de encontrar alternativas para promover a recuperação do solo. Por outro lado, um grupo de cinco agricultores mudou o sistema por convicção ideológica, por entender que o meio ambiente, a natureza e os seres vivos precisam de cuidados especiais para que o ser humano possa viver melhor e poder deixar um ambiente mais saudável para as próximas gerações.

Dos motivos apontados pelos agricultores para a tomada de decisão em mudar a matriz produtiva, as repostas que mais chamaram a atenção, estão relacionadas à saúde familiar, pois doze famílias de agricultores decidiram mudar devido a problemas relacionados com a saúde de algum membro familiar. Este fato fica evidenciado nas declarações dos agricultores. Um disse que se um dia seu filho lhe pedisse um pêssego para comer não teria coragem de atender seu pedido e responderia da seguinte maneira: "Não, meu filho, este não pode comer porque ele tem veneno" e complementa dizendo que "se não quero que minha família coma uma fruta contaminada, porque outros podem comer?'. Este agricultor teve sérios problemas de intoxicação pelo uso excessivo de produtos químicos no pomar de pessegueiro. Convicto da mudança realizou visitas técnicas a centros de pesquisas para conhecer o trabalho de produção ecológica. Em uma dessa visitas, após conhecer os métodos de produção agroecológica afirmou que: "pra mim foi como estar numa peca escura e de repente se abrir uma janela e dali eu voltei para casa sem medo de errar e estou tocando até boje". A preocupação com a saúde não só das famílias que produzem, mas também dos consumidores, pode ser observado em outros estudos similares. Como no relato de um agricultor que teve como principal motivo em mudar, o desejo de ter uma melhor qualidade de vida e foi em busca de:

"Um meio de vida melhor, produzindo um produto natural, sem falar que evitando os agrotóxicos, está-se vendendo um produto que não prejudicam os outros que é saudável. O mais importante nisso tudo é a saúde das pessoas que, hoje em dia, está em primeiro lugar (CASALINHO, 2003, p.67)." 
Outra situação comum para muitos agricultores foi abandonar o cultivo do fumo e buscar uma alternativa mais saudável e menos penosa. Este fato é destacado por uma agricultora que após descontinuar o plantio de fumo dizia: "A gente só sabe o que é parar de plantar fumo depois que para, porque é a mesma coisa que sair de uma prisão". Para esta agricultora foi a decisão mais acertada da vida deles e confessa ter recebido pressão da família para continuar a plantar fumo, pois as hortaliças produzidas não tinham mercado e se perdia muito, então a agricultora se manifestou da seguinte forma: "Se a gente não conseguir vender o fumo, nós não vamos comer e nem o animal come, nem pra terra ele serve, mas na feira o que sobrar, volta pra casa e vai ter a mesa farta e até pode se dar para os vizinhos e também tratar os animais".

Passados vários anos, todos estão contentes, porque estão plantando e colhendo alimentos saudáveis não só para a família, mas também para os consumidores em geral. As eventuais sobras de verduras das feiras tornamse uma alternativa de alimento para as aves, conforme foi relatado por dois agricultores os quais disseram que grande parte da alimentação das galinhas caipiras é constituída das verduras que voltam para casa e também daquelas danificadas e sem qualidade para a comercialização.

Portanto, são muitos os motivos que levou este grupo de agricultores a tomar a decisão de mudar o processo de produção, porém três aparecem com mais intensidade. As questões voltadas ao aumento de renda através da valorização da produção por meio da venda direta ao consumidor, as questões relacionadas à saúde familiar e os cuidados com o meio ambiente. $\mathrm{Na}$ verdade estes três motivos juntos visam oferecer uma condição de vida mais saudável para a família e a preservação do meio ambiente promovendo o crescimento e a manutenção da unidade de produção em bases sustentáveis. 
Processo de tomada de decisao e a racionalidade administratıva na mudança do sistema de produção convencional para o de base ecológica na agricultura familiar

Quadro 1. Resumo das informações prestadas por 20 agricultores da ARPASUL e da Cooperativa Sul Ecológica de Pelotas/RS visando a tomada de decisão para a mudança de sistema de produção agrícola da unidade familiar.

\begin{tabular}{|c|c|c|c|c|c|c|}
\hline $\mathbf{N}^{\circ}$ & Familia & $\begin{array}{l}\text { Localidade / } \\
\text { Município }\end{array}$ & $\begin{array}{c}\text { Cultivos } \\
\text { anteriores e } \\
\text { sistema de prod. }\end{array}$ & $\begin{array}{l}\text { Problemas } \\
\text { enfrentados }\end{array}$ & $\begin{array}{l}\text { Tempo na } \\
\text { produção } \\
\text { ecológica }\end{array}$ & $\begin{array}{c}\text { Motivos que o } \\
\text { levaram a tomar } \\
\text { a decisão da } \\
\text { mudança }\end{array}$ \\
\hline 1 & Bersch & Remanso -Canguçu & $\begin{array}{c}\text { Soja, trigo, cebola } \\
\text { e leite. Sistema } \\
\text { convencional e } \\
\text { uso de insumos } \\
\text { químicos }\end{array}$ & $\begin{array}{c}\text { Baixa } \\
\text { rentabilidade, } \\
\text { problemas de } \\
\text { mercado; pagar } \\
\text { arrendamento } \\
\text { para plantar } \\
\text { soja }\end{array}$ & 12 anos & $\begin{array}{c}\text { Buscar novas } \\
\text { alternativas de } \\
\text { renda; diversificar } \\
\text { a produção (frutas } \\
\text { e hortaliças) e } \\
\text { deixar de pagar } \\
\text { arrendamento }\end{array}$ \\
\hline 2 & Barbosa & $\begin{array}{l}\text { Remanso - } \\
\text { Canguçu }\end{array}$ & $\begin{array}{c}\text { Soja, milho, feijão } \\
\text { e fumo. Uso } \\
\text { intensivo do solo } \\
\text { e cultivo sem } \\
\text { adubo }\end{array}$ & $\begin{array}{c}\text { Baixa } \\
\text { rentabilidade } \\
\text { esgotamento } \\
\text { do solo, pouca } \\
\text { mão-de-obra }\end{array}$ & 12 anos & $\begin{array}{c}\text { Diversificar } \\
\text { (hortaliças e } \\
\text { frutas);obter renda } \\
\text { semanal, diminuir } \\
\text { os riscos (seca) } \\
\text { e consciência } \\
\text { ecológica e sair do } \\
\text { fumo. }\end{array}$ \\
\hline 3 & Bastos & $\begin{array}{c}\text { Ilha dos } \\
\text { Marinheiros - Rio } \\
\text { Grande }\end{array}$ & $\begin{array}{c}\text { Cebola } \\
\text { convencional e } \\
\text { algumas hortaliças }\end{array}$ & $\begin{array}{c}\text { Cultivo intenso } \\
\text { de cebola. } \\
\text { Problemas } \\
\text { de mercado. } \\
\text { Preocupações } \\
\text { com o meio } \\
\text { ambiente. }\end{array}$ & 7 anos & $\begin{array}{c}\text { Consciência } \\
\text { ecológica; preservar } \\
\text { o meio ambiente } \\
\text { diversificar } \\
\text { a produção } \\
\text { (hortaliças, flores, } \\
\text { vinho jurupinga e } \\
\text { ovos). }\end{array}$ \\
\hline 4 & Edwin & $\begin{array}{c}\text { Passo do Pinto } \\
\text { - São Lourenço } \\
\text { do Sul }\end{array}$ & $\begin{array}{c}\text { Leite, milho e } \\
\text { batata no sistema } \\
\text { convencional, } \\
\text { criação de suínos } \\
\text { confinados e } \\
\text { prod. de mel }\end{array}$ & $\begin{array}{c}\text { Problemas } \\
\text { de mercado } \\
\text { para o mel e } \\
\text { suínos. Baixa } \\
\text { rentabilidade do } \\
\text { leite. Mercado } \\
\text { da batata por } \\
\text { atravessadores. } \\
\text { Saúde familiar }\end{array}$ & 12 anos & $\begin{array}{c}\text { Organizar } \\
\text { mercado, } \\
\text { diversificar } \\
\text { a produção } \\
\text { (hortaliças) } \\
\text { aumentar a } \\
\text { renda; produção } \\
\text { mais saudável e } \\
\text { viabilizar produção } \\
\text { de leite }\end{array}$ \\
\hline 5 & Holz & Remanso -Canguçu & $\begin{array}{c}\text { Soja, milho, } \\
\text { feijão no sistema } \\
\text { convencional } \\
\text { com baixo uso de } \\
\text { tecnologia }\end{array}$ & $\begin{array}{c}\text { Problemas de } \\
\text { mercado e baixa } \\
\text { renda com o } \\
\text { cultivo da soja, } \\
\text { única renda } \\
\text { agrícola. }\end{array}$ & 12 anos & $\begin{array}{c}\text { Auxiliar na } \\
\text { criação da ARPA- } \\
\text { SUL, organizar } \\
\text { o mercado; } \\
\text { convicção } \\
\text { ecológica, } \\
\text { mais renda e } \\
\text { preservação do } \\
\text { meio ambiente. }\end{array}$ \\
\hline
\end{tabular}




\begin{tabular}{|c|c|c|c|c|c|c|}
\hline $\mathbf{N}^{\circ}$ & Familia & $\begin{array}{l}\text { Localidade / } \\
\text { Município }\end{array}$ & $\begin{array}{c}\text { Cultivos } \\
\text { anteriores e } \\
\text { sistema de prod. }\end{array}$ & $\begin{array}{c}\text { Problemas } \\
\text { enfrentados }\end{array}$ & $\begin{array}{l}\text { Tempo na } \\
\text { produção } \\
\text { ecológica }\end{array}$ & $\begin{array}{c}\text { Motivos que o } \\
\text { levaram a tomar } \\
\text { a decisão da } \\
\text { mudança }\end{array}$ \\
\hline 6 & Kuhn & $\begin{array}{c}\text { Estrada da Gama - } \\
\text { Pelotas }\end{array}$ & $\begin{array}{c}\text { fumo, batata, } \\
\text { repolho, leite com } \\
\text { baixa produtiv. e } \\
\text { com custo elevado } \\
\text { de produção }\end{array}$ & $\begin{array}{c}\text { Baixa } \\
\text { rentabilidade, } \\
\text { poucas opções } \\
\text { de venda da } \\
\text { produção } \\
\text { (exceção para o } \\
\text { fumo e leite) }\end{array}$ & 7 anos & \begin{tabular}{|c|} 
Diversificar \\
a produção \\
(hortaliças); \\
aumentar a renda; \\
acabar com o \\
fumo; preocupação \\
com a saúde e o \\
meio ambiente.
\end{tabular} \\
\hline 7 & Leal & $\begin{array}{c}\text { Coxilha dos } \\
\text { Campos - Canguçu }\end{array}$ & $\begin{array}{c}\text { Cultivos diversos } \\
\text { (batata, feijão, } \\
\text { milho, hortaliças). } \\
\text { Produção } \\
\text { individual e sem } \\
\text { assistência técnica }\end{array}$ & \begin{tabular}{|c|} 
Falta de \\
mercado; \\
venda para \\
atravessadores, \\
baixo preço; \\
Perda de muita \\
produção \\
por falta de \\
compradores \\
\end{tabular} & 12 anos & \begin{tabular}{|c|} 
Manter relação \\
direta com o \\
mercado; obter \\
renda semanal; \\
manter a familia na \\
unidade, produzir \\
alimento sadio \\
para a familia e \\
consumidor \\
\end{tabular} \\
\hline 8 & Leizke & Remanso-Canguçu & $\begin{array}{c}\text { Soja e trigo, } \\
\text { com grande } \\
\text { dependência } \\
\text { de insumos, } \\
\text { máquinas e mão- } \\
\text { de-obra }\end{array}$ & $\begin{array}{c}\text { Baixa } \\
\text { remuneração da } \\
\text { produção; falta } \\
\text { de mercado, } \\
\text { renda bi-anual e } \\
\text { dependência de } \\
\text { atravessadores }\end{array}$ & 2 anos & \begin{tabular}{|c} 
Buscar novas \\
alternativas, \\
obter mais renda \\
e também por \\
tratar-se de uma \\
forma de produção \\
mais saudável, sem \\
agrotóxicos. \\
\end{tabular} \\
\hline 9 & Mühlenberg & $\begin{array}{c}\text { Butiá/São } \\
\text { Lourenço do Sul }\end{array}$ & $\begin{array}{c}\text { Batata, milho, } \\
\text { feijão, arroz de } \\
\text { sequeiro no sist. } \\
\text { convencional e } \\
\text { muito uso de fert. } \\
\text { e quimicos }\end{array}$ & \begin{tabular}{|c|} 
Problemas \\
sérios de \\
saúde com \\
agrotóxicos \\
na batata. \\
Venda para \\
atravessadores. \\
Falta de opções \\
de mercado \\
\end{tabular} & 12 anos & $\begin{array}{c}\text { Decisão tomada } \\
\text { pelos filhos em } \\
\text { mudar o sistema. } \\
\text { Desejo de viver } \\
\text { muito tempo. } \\
\text { Preservar o } \\
\text { meio ambiente } \\
\text { e produção } \\
\text { sustentável. }\end{array}$ \\
\hline 10 & Peter & Remanso -Canguçu & $\begin{array}{c}\text { Fumo, soja, } \\
\text { milho, e leite com } \\
\text { poucos recursos } \\
\text { financ e baixa } \\
\text { tecnologia }\end{array}$ & $\begin{array}{c}\text { Chuva de pedra } \\
\text { que liquidou } \\
\text { o fumo; uso } \\
\text { intensivo de } \\
\text { veneno, e pouca } \\
\text { renda; soja } \\
\text { esgotamento do } \\
\text { solo. }\end{array}$ & 12 anos & $\begin{array}{c}\text { Buscar aumento } \\
\text { de renda através } \\
\text { da diversificação } \\
\text { (frutas, hortaliças, } \\
\text { milho, feijão, } \\
\text { leite); saúde para a } \\
\text { familia e recuperar } \\
\text { solo. }\end{array}$ \\
\hline
\end{tabular}


Processo de tomada de decisão e a racionalidade administrativa na mudança do sistema de produção convencional para o de base ecológica na agricultura familiar

Quadro 1. Continuação

\begin{tabular}{|c|c|c|c|c|c|c|}
\hline $\mathbf{N}^{\circ}$ & Família & $\begin{array}{c}\text { Localidade / } \\
\text { Município }\end{array}$ & $\begin{array}{l}\text { Cultivos } \\
\text { anteriores }\end{array}$ & $\begin{array}{l}\text { Problemas } \\
\text { enfrentados }\end{array}$ & $\begin{array}{l}\text { Tempo na } \\
\text { produção } \\
\text { ecológica }\end{array}$ & $\begin{array}{c}\text { Motivos que o } \\
\text { levaram a tomar } \\
\text { a decisão da } \\
\text { mudança }\end{array}$ \\
\hline 11 & Quintana & $\begin{array}{l}\text { Coxilha dos } \\
\text { Cunha/ } \\
\text { Canguçu }\end{array}$ & $\begin{array}{c}\text { Feijão, milho, } \\
\text { alho, cebola, } \\
\text { batata, leite no } \\
\text { sistema conv. } \\
\text { e com uso de } \\
\text { baixa tecnologia }\end{array}$ & $\begin{array}{l}\text { Baixa renda } \\
\text { familiar, } \\
\text { poucas opções } \\
\text { de mercado; } \\
\text { dependência } \\
\text { exclusiva de } \\
\text { atravessadores. } \\
\text { Saúde familiar }\end{array}$ & 4 anos & $\begin{array}{c}\text { Buscar novas } \\
\text { alternativas de } \\
\text { renda semanal; } \\
\text { diversificar a } \\
\text { produção mercado } \\
\text { direto e cuidados } \\
\text { com a saúde da } \\
\text { família. }\end{array}$ \\
\hline 12 & Scheer & $\begin{array}{c}\text { São Domingos } \\
\text {-Morro } \\
\text { Redondo }\end{array}$ & $\begin{array}{c}\text { Cebola, batata, } \\
\text { feijão, leite e } \\
\text { frangos. Uso de } \\
\text { ad. químicos }\end{array}$ & $\begin{array}{c}\text { Baixa renda } \\
\text { familiar, buscar } \\
\text { mercado para a } \\
\text { produção que era } \\
\text { vendida de casa em } \\
\text { casa. }\end{array}$ & 8 anos & $\begin{array}{c}\text { Diversificar } \\
\text { a produção; } \\
\text { diminuir os riscos, } \\
\text { aumentar a renda } \\
\text { na propriedade, } \\
\text { preservar o solo, } \\
\text { meio ambiente e } \\
\text { socializar com a } \\
\text { comun.. }\end{array}$ \\
\hline 13 & Scheunemann & $\begin{array}{c}\text { Monte Bonito - } \\
\text { Pelotas }\end{array}$ & $\begin{array}{c}\text { Soja, milho, } \\
\text { feijão, batata e } \\
\text { leite no interior } \\
\text { de Canguçu em } \\
\text { área precária }\end{array}$ & $\begin{array}{c}\text { Pouca renda } \\
\text { familiar, problemas } \\
\text { de mercado, perda } \\
\text { de produtos e } \\
\text { preocupações com } \\
\text { uso dos venenos }\end{array}$ & 14 anos & $\begin{array}{c}\text { Organizar } \\
\text { mercado; criar } \\
\text { associação para } \\
\text { facilitar compras de } \\
\text { insumos; aumentar } \\
\text { a renda e convicção } \\
\text { pela ecologia. } \\
\text { Saúde familiar }\end{array}$ \\
\hline 14 & Schiavon & $\begin{array}{c}\text { Colônia Maciel } \\
\text {-Pelotas }\end{array}$ & $\begin{array}{c}\text { Produtor de } \\
\text { pêssego conv. } \\
\text { com muito } \\
\text { químico, milho } \\
\text { e feijão }\end{array}$ & $\begin{array}{c}\text { Problemas } \\
\text { sérios de saúde; } \\
\text { intoxicação por } \\
\text { agrotóxicos; } \\
\text { problemas de } \\
\text { mercado com o } \\
\text { pêssego. }\end{array}$ & 14 anos & $\begin{array}{l}\text { Melhorar a saúde } \\
\text { familiar; produzir } \\
\text { alimentos mais } \\
\text { limpo para o } \\
\text { consumidor; } \\
\text { recuperar o solo } \\
\text { e diversificar } \\
\text { produção }\end{array}$ \\
\hline 15 & Schiller & $\begin{array}{l}\text { Morro } \\
\text { Redondo }\end{array}$ & $\begin{array}{c}\text { Fumo e } \\
\text { leite.Alta } \\
\text { dependência } \\
\text { da emp. } \\
\text { integradoras }\end{array}$ & $\begin{array}{c}\text { Problemas de } \\
\text { saúde na familia. } \\
\text { Cultivo do fumo, } \\
\text { uso de muita mão- } \\
\text { de-obra e receita } \\
\text { uma vez por ano. }\end{array}$ & 11 anos & $\begin{array}{l}\text { Produzir mais } \\
\text { saudável para } \\
\text { a familia e } \\
\text { consumidores; } \\
\text { obter renda } \\
\text { semanal e } \\
\text { novas opções } \\
\text { de produtos } \\
\text { processados. }\end{array}$ \\
\hline
\end{tabular}




\begin{tabular}{|c|c|c|c|c|c|c|}
\hline $\mathbf{N}^{\circ}$ & Familia & $\begin{array}{c}\text { Localidade / } \\
\text { Município }\end{array}$ & $\begin{array}{l}\text { Cultivos } \\
\text { anteriores }\end{array}$ & $\begin{array}{l}\text { Problemas } \\
\text { enfrentados }\end{array}$ & $\begin{array}{l}\text { Tempo na } \\
\text { produção } \\
\text { ecológica }\end{array}$ & $\begin{array}{c}\text { Motivos que o } \\
\text { levaram a tomar } \\
\text { a decisão da } \\
\text { mudança }\end{array}$ \\
\hline 16 & Silva & $\begin{array}{c}\text { Bolacha/Rio } \\
\text { Grande }\end{array}$ & $\begin{array}{c}\text { Hortaliças } \\
\text { diversas } \\
\text { no sistema } \\
\text { convencional }\end{array}$ & $\begin{array}{c}\text { Uso de muito } \\
\text { químico, } \\
\text { problemas com } \\
\text { o solo e com a } \\
\text { familia e falta de } \\
\text { mercado. }\end{array}$ & 10 anos & $\begin{array}{c}\text { Melhorar a saúde } \\
\text { da familia, dos } \\
\text { consumidores e } \\
\text { das crianças e com } \\
\text { o meio ambiente. }\end{array}$ \\
\hline 17 & Silva & $\begin{array}{l}\text { Praia do Mar } \\
\text { Grosso - São } \\
\text { José do Norte }\end{array}$ & $\begin{array}{c}\text { Cebola, feijão } \\
\text { miúdo, milho } \\
\text { e horta. Com } \\
\text { poucas opções } \\
\text { de prod. }\end{array}$ & $\begin{array}{l}\text { Baixo rendimento } \\
\text { da cebola; não } \\
\text { depender somente } \\
\text { de um produto e } \\
\text { cuidar do solo. }\end{array}$ & 8 anos & \begin{tabular}{|c|} 
Consciência \\
ecológica em \\
preservar o meio \\
ambiente e a \\
saúde da familia; \\
diversificar a \\
produção e a renda \\
(galinhas caipiras, \\
ovos).
\end{tabular} \\
\hline 18 & Storck & $\begin{array}{c}\text { São Domingos } \\
\text { - Turuçu }\end{array}$ & $\begin{array}{c}\text { Soja, fumo } \\
\text { e milho } \\
\text { no sistema } \\
\text { convencional. } \\
\text { Com muito } \\
\text { adubo e prod. } \\
\text { químicos } \\
\end{array}$ & $\begin{array}{c}\text { Baixa rentabilidade } \\
\text { da soja, uso } \\
\text { excessivo de } \\
\text { químicos; dividas } \\
\text { com financiamento } \\
\text { da lavoura; falta de } \\
\text { máq. } \\
\end{array}$ & 11 anos & $\begin{array}{c}\text { Diversificar a } \\
\text { produção, melhorar } \\
\text { a renda e uso da } \\
\text { mão-de-obra; } \\
\text { diminuir as dívidas } \\
\text { e riscos. }\end{array}$ \\
\hline 19 & Voigt & Arroio do Padre & $\begin{array}{c}\text { Monocultivo de } \\
\text { repolho com } \\
\text { muito químicos } \\
\text { e produção de } \\
\text { leite }\end{array}$ & $\begin{array}{c}\text { Intoxicação } \\
\text { familiar pelo } \\
\text { excesso de } \\
\text { químicos. } \\
\text { Esgotamento } \\
\text { do solo pelo uso } \\
\text { excessivo de uréia. }\end{array}$ & 8 anos & $\begin{array}{c}\text { Em primeiro lugar } \\
\text { saúde familiar; } \\
\text { recuperar o solo; } \\
\text { diversificar a } \\
\text { produção e buscar } \\
\text { mercado através da } \\
\text { venda direta. }\end{array}$ \\
\hline 20 & Wickboldt & Arroio do Padre & $\begin{array}{l}\text { Monocultivo } \\
\text { do Fumo com } \\
\text { muito veneno }\end{array}$ & $\begin{array}{l}\text { Sérios problemas } \\
\text { de intoxicação da } \\
\text { familia. Excesso } \\
\text { de trabalho e } \\
\text { esgotamento do } \\
\text { solo. }\end{array}$ & 12 anos & $\begin{array}{l}\text { Melhorar a } \\
\text { saúde da familia, } \\
\text { diversificação } \\
\text { da produção } \\
\text { (hortaliças); } \\
\text { recuperar solo e } \\
\text { venda direta ao } \\
\text { consumidor. }\end{array}$ \\
\hline
\end{tabular}

\section{CONSIDERAÇÕES FINAIS}

A tomada de decisão na agricultura familiar nem sempre é um processo simples e fácil como poôde ser verificado neste trabalho, pois 
Processo de tomada de decisão e a racionalidade administrativa na mudança do sistema de produção convencional para o de base ecológica na agricultura familiar

envolve uma série de condicionantes relacionados aos aspectos econômicos, sociais e ambientais, como: o aumento da renda, a organização do trabalho, a satisfação familiar, a solidariedade e companheirismo, os cuidados com o meio ambiente, são aspectos importantes para a maioria das familias engajadas em um processo organizacional, participativo, coletivo, em que a manutenção da saúde e bem estar da família, estão acima de qualquer decisão. Observou-se também que, em quase todas as famílias, foi fundamental o apoio institucional das organizações oferecendo apoio técnico, logístico e até financeiro. Neste sentido, a atuação do CAPA foi estratégica para motivar e impulsionar esses agricultores a tomarem a decisão da mudança do sistema de produção.

Nos depoimentos, um dos agricultores afirmou que existem três aspectos importantes na produção ecológica: a vida do agricultor, a saúde do consumidor e a preservafão dos recursos naturais como a terra e a água e o resultado dessa interação é que todos saem ganhando. Para os agricultores que participam das feiras, há um incentivo a mais e que lhes enche de orgulho, que é a satisfação dos consumidores. Isto é percebido no depoimento de um dos agricultores, que ao se aproximar uma senhora com sua filha, esta lhe disse: "então és tu que desde os seis anos de idade alimenta ela com seus produtos", e o agricultor completou "isto é gratificante para a gente que produz alimentos, porque está dando o que é bom para outras familias".

O trabalho realizado com os agricultores da ARPA-SUL e da Cooperativa Sul Ecológica apurou informações importantes no contexto decisional, o que nos leva a fazer uma reflexão e obter uma aprendizagem com esses agricultores em relação à tomada de decisão. Como disse um dos agricultores "foi a decisão mais acertada da minha vida", referindo-se à mudança para a agroecologia e associando-se à ARPA-SUL. Foi possível verificar em todas as entrevistas, a satisfação do agricultor em fazer parte deste grupo e que um dia tomou a decisão de abandonar o sistema de cultivo convencional e que hoje, além de ser um produtor ecológico, atua de várias formas divulgando seu trabalho, mostrando a importância de se ofertar um alimento mais limpo e saudável para os consumidores. Quando da realização da feira em uma escola de $1^{\circ}$ grau e vendo o grande interesse das crianças em querer saber mais sobre os produtos e como são produzidos, disse um dos agricultores: "Olha, mesmo que se eu não tivesse vendido nada, nem um molho de couve, só a satisfação de ver a cara daquela criançada perguntando e o interesse que eles tinham, pra mim já teria valido a pena". Este trabalho de 
divulgação e educação ecológica vem sendo feito pela diretoria da ARPA-SUL e com certeza terá um efeito multiplicador ao longo do tempo.

Este trabalho não teve por finalidade apurar a renda obtida em cada familia, mas o que pode se verificar e também ouvir dos agricultores, que todos estão melhores atualmente do que antes, pois puderam melhorar a infraestrutura de produção, moradia, conforto e o convívio social têm sido mais intenso não só dos agricultores, mas de toda a família.

A amostra de agricultores do trabalho é pequena em relação ao universo dos agricultores agroecológicos. No entanto, como os resultados refletem as preocupações diagnosticadas em outros estudos e também a visão de técnicos de entidades governamentais e não-governamentais, isto leva a crer que as questões relativas à racionalidade decisional podem ser representativas de um universo maior de produtores. Desta forma, analisando as informações desses agricultores familiares já inseridos no processo de produção de base ecológica, pode-se concluir que:

1. Independentemente do tamanho da unidade familiar, ou do volume de produção, ela deve estar organizada em seu processo de produção e associada a uma entidade para se inserir no mercado, porque isoladamente é muito mais difícil sobreviver e manter-se na atividade;

2. O processo de tomada de decisão ocorre no âmbito da unidade familiar levando-se em consideração aspectos sociais, ambientais, econômicos, saúde, bem estar familiar e ideológico;

3. Os agricultores que participaram desta pesquisa demonstraram muita satisfação com aquilo que estão fazendo atualmente, convictos de que tomaram a decisão correta em mudar do sistema de produção convencional para o de base ecológica;

4. De uma maneira geral, pode-se perceber nas entrevistas, de que a situação atual das famílias está muito melhor que a anterior por vários motivos, porém principalmente pelo fato de terem resgatado a auto-estima, produzindo um alimento mais saudável preservando o patrimônio natural e ainda obterem uma renda distribuída ao longo do ano.

Finalizando, pode-se dizer que entre as motivações dos agricultores captadas pela pesquisa está, acima de tudo, a preocupação em produzir-se de 
Processo de tomada de decisão e a racionalidade administrativa na mudança do sistema de produção convencional para o de base ecológica na agricultura familiar

forma ecologicamente correta e poder ofertar diretamente aos consumidores alimentos mais saudáveis, satisfazendo não somente aos agricultores, mas atendendo os interesses e preferência dos consumidores de uma forma geral. Enfim, um processo de mudança envolve estratégias, organização interna e externa, racionalidade, tomada de decisão, apoio institucional e acima de tudo vontade e persistência em mudar na busca dos objetivos e metas familiares e das instituições.

\section{REFERÊNCIAS}

ALBUQUERQUE, A F; ESCRIVÃO FILHO, E.E. Administrar é decidir: a visão de Herbert A Simon. Revista DCS on Line. Três Lagoas, v.2, n.1, nov. 2007

BANA E; COSTA, C. A Três convicções fundamentais na prática do apoio à decisão. Revista Pesquisa OperacionaI, v.13, n.l, jun. 1993.

BARROS, G. Racionalidade e organizações: um estudo sobre comportamento econômico na obra de Herbert A. Simon. 2004. 145 f. Dissertação (Mestrado em Economia) - Faculdade de Economia, Administração e Ciências Contábeis, Universidade de São Paulo, São Paulo.

BISSOTO, M.L. Auto-organização, cognição corporificada e os princípios da racionalidade limitada. Ciências \& Cognição; Ano 4, v.11, p.80-90. 2007. Disponível em http://www.cienciasecognicao.org/. Acesso em 20.06.2009

CAPORAL, F. R.; COSTABEBER, J. A Agroecologia e desenvolvimento rural sustentável: perspectivas para uma nova Extensão Rural. Agroecologia e Desenvolvimento Rural Sustentável, v.l, n.l, p.16-37, jan./mar. 2000.

CASALINHO, H.D.; Qualidade do solo como indicador de sustentabilidade de agroecossistemas. 2003, 192 f. Tese (Doutorado)Universidade Federal de Pelotas.

CHAYANOV, A V. La organización de la unidad econômica campesina. 1. ed., Buenos Aires: Nueva Visión, 1974. 342 p. 
CHIAVENATO, I. Administração de recursos humanos: fundamentos básicos. 6. ed. São Paulo. Atlas, 2007. 256p.

DAROLT, M.R. As dimensões da sustentabilidade: um estudo da agricultura orgânica na região metropolitana de Curitiba, Paraná. 2000. $298 \mathrm{f}$. Tese (Doutorado em Meio Ambiente e Desenvolvimento)-Universidade Federal do Paraná, Curitiba

ENSSLIN, L.; MONTIBELLER NETO, G ; NORONHA, S. M. Apoio à decisão: metodologias para estruturação de problemas e avaliação multicritério de alternativas. Florianópolis: Insular, 2001. 296p.

GOMES, M.C. Apoio à decisão em empresas familiares em processo de evolução: um modelo multicritérios em um estudo de caso-, na indústria de conservas de Pelotas-RS, 2001. 417f. Tese (Doutorado em Engenharia de Produção)-Universidade Federal de Santa Catarina, Florianópolis

LIMA, A P.de et al. Administração da unidade de produção familiar: modalidades de trabalho com os agricultores. 3 ed. - Ijuí: UNIJUI, 2005, 224p

LOPES, A et al. A complexidade decisional na unidade familiar de base agroecológica: um caso ligado a ARPA-SUL, município de PelotasRS. CONGRESSO BRASILEIRO DE AGROECOLOGIA, 3, 2005. Florianópolis. Anais. Florianópolis: Epagri, 2005.1 CD-ROM.

PAYMES, MA.M; SILVEIRA, M.A. A racionalidade econômica do empresário familiar. Jaguariúna: Embrapa-CNPMA, 1997. 21p, (EmbrapaCNPMA, Documentos 10)

SIMON, H.A. Comportamento administrativo: um estudo dos processos de decisões nas organizações administrativas. 2.ed. Rio de Janeiro: FGV, 1970. 279p

VERONA, L.A.F. Análise de sustentabilidade de agroecossistemas de base familiar e em transição agroecológica na região sul do Rio Grande do Sul. 2008. 160f. Tese (Doutorado em Produção Vegetal)-Faculdade de Agronomia, Universidade Federal de Pelotas, Pelotas. 